\title{
Proceeding
}

8th INSHS International Christmas Sport Scientific Conference, 5-7 December 2013. International Network of Sport and Health

Science. Szombathely, Hungary

\section{The serve in under 12-13 Italian volleyball team}

\author{
FABIO PARISI ${ }^{1}$, GAETANO RAIOLA ${ }^{2}$ \\ ${ }^{1}$ High Education Student SWARM - University of West-Hungary \\ ${ }^{2}$ Adjunct professor, University of Basilicata, Italy
}

\begin{abstract}
Parisi, F., Casalino, C. \& Raiola, G. (2014). The serve in under 12-13 Italian volleyball team. J. Hum. Sport Exerc., 9(Proc1), pp.S588-S591. The serve is the technical skill with which a rally of a game of volleyball begins, and it can be performed by underhand, by a high float or drive and by a high jump. At the request of the coaches of national youth teams, the Italian Volleyball Federation (FIPAV) has adopted the mandatory underhand serve only for Under-12 and under 13 championships in order to favor the continuity of the game movement and passes of the ball over the net, which would be compromised in the event of a volleyball athlete who is particularly good at high jump serves. Although the abutment from the bottom appears to be more easily learned, not having the characteristics of offensiveness, must be abandoned as soon as it is able to perform the services more insidious. The increase in strength up to 11 years is very low and no difference between the sexes, he observes a slight increase up to 15 years, then intervenes when the phase of maximum development that leads to the peak at age 18. In this period there is also a progressive differentiation between females and males with a surge in favor of males estimated at strength of about $40 \%$ greater than that of peers. The aim of this preliminary study was to see if an experimental study can be implemented, preceded by a pilot study in order to verify the hypothesis for the accuracy of the mandatory rule for the Under-12 and Under-13. Key words: COGNITIVE ECOLOGICAL-DYNAMIC APPROACH, GAME RULES, PRELIMINARY WORK.
\end{abstract}

Corresponding author. High Education Student SWARM - University of West-Hungary.

E-mail: parisifabio19@gmail.com

8th INSHS International Christmas Sport Scientific Conference, 5-7 December 2013. International Network of Sport and Health Science. Szombathely, Hungary.

JOURNAL OF HUMAN SPORT \& EXERCISE ISSN 1988-5202

(C) Faculty of Education. University of Alicante

doi:10.14198/jhse.2014.9.Proc1.51

VOLUME 9 | Proc1 | 2014 | S588 


\section{INTRODUCTION}

Volleyball is a game sport where the study is in human and experimental sciences according to an ecological educational way, it includes some aspects of human science and experimental science to analyze descriptively the movement (Raiola, 2012a). So on, didactics of volleyball into the educate program for coaches/trainers/technicians have to teach exactly by proper methods, distinctly for skills (Raiola, 2012b). In volleyball individual skills, such as the serve, is minor part of technical aspect of the analysis of the training, but it is fundamental skill of volleyball, especially for young athlete. The Serve is the technical skill with which a rally of a game of volleyball begins, and it can be performed by underhand, by a high float or drive and by a high jump. At the request of the coaches of national youth teams, the Italian Volleyball Federation (FIPAV) has adopted the mandatory underhand serve only for Under-12 and under 13 championships in order to favor the continuity of the game movement and passes of the ball over the net, which would be compromised in the event of a volleyball athlete who is particularly good at high jump serves. Although the serve from below seems to be more easily learned, not having the characteristics of offensiveness, must be abandoned as soon as it is able to perform the services more insidious. The underhand serve is only taught with a prescriptive method of teaching within a cognitive approach while other types of serves can be taught with an ecological-dynamic approach via heuristic learning. The increase in strength up to 11 years is very low and there is no difference between the sexes, there is a slight increase up to 15 years, then the phase of maximum development that leads to the peak at age 18. In this period there is also a progressive differentiation between females and males with a surge in favor of males estimated at a strength of about $40 \%$ greater than that of their female peers. The learning modalities, for psychological reasons, vary between the sexes. The girls are brought naturally to seek the help of the teacher, to follow his instructions. On the contrary, the boys resort to the help of the teacher only as a last resort. When it comes to motivating athletes males respond better to the stress resulting from the comparison tasks or bound by time, an approach that does not produce results with females. There was no difference on learning the same engines.

The aim of this preliminary study was to explore if an experimental study can be implemented, preceded by a pilot study in order to verify the hypothesis for the accuracy of the mandatory rule for the Under-12 and Under-13. "The results will be useful for identifying the errors and to analyze the causes, to suggest different ways of analysis and self-analysis of technical movements for educational purposes, and also for a hypothetical different way to teach specific technical gestures, using video feedback" (Raiola et al., 2013). "The survey of data is entrusted to performance analysis methodology, carried out gradually with the help of experts, coaches and analysts".

\section{METHODOLOGY}

The work was in its preliminary stages; therefore the method was theoretical with the collection of documents on the rules of play, the educational teaching aspects, and on the expressiveness of force. It is also argumentative and calls for the preparation of a research design for a pilot study. The research design provided the experimental method with collection of data on athletes receiving batting from below or from above in both categories Under 12 and 13 in the identification of indicators and descriptors of learning. It also provided a range of quantitative and qualitative tests that measure the effectiveness of the measure. The sample of the pilot study was composed of a group of 20 athletes aged between 11 and 14 years, 10 females and 10 males, all from the "Associazione Sportiva Dilettantistica Elisa volley Pomigliano". In each batch of training were alternate underhand and high float serving techniques employed. In training, the athletes will be divided into two teams: 
1) Team A composed of 10 subjects of mixed sex and age and with no experience of the game of volleyball;

2) Team B will consist of 10 subjects of mixed sex and age but with experience in the game of volleyball at least one year.

The workouts will be performed 3 times a week, for one hour and a half each, with the presence of two coaches, always the same. In each practice match underhand serves and high jump serves will be alternated, the coach will mark the data including: correctincorrect serves and receptions that allow the game to continue which will be placed in correlation with the data on the learning. In official competitions athletes will participate in the Under- 12 Women's Championship and the Under- 13 men's championship, according to the rules decided by FIPAV. Then the two teams will be divided simply on the basis of chronological age and sex of each individual athlete. The matches will take place from February to April and also in this context, the coach will mark every keystroke made by both teams. The technique will be, as already mentioned, only one from underhand for regulatory reasons but also in this case will be scored the number of service, the number of errors made and how many receipts have actually allowed the continuity in the actions of the game. The data thus collected, either through training or through the official matches, will be compared in order to determine the real difference on maintaining the serve from below or from above, and if there really is a need for this differentiation in order to allow a greater number of exchanges of the ball over the net. In addition, athletes will train together, so examine gender differences that could lead to the foundation of championships exclusively female and male-only, compared to a single mixed championship.

\section{EXPECTED RESULTS \& DISCUSSION}

The expression of force is not dependent on chronological age but by biological age; the learning of motor skills are equal regardless of the differences in age between the 2 categories. The research design includes an experimental method with the collection of data on athletes receiving serves from both underhand and high jumps in both the Under-12 and Under-13 categories with the identification of indicators and descriptors of the learning. It also includes a series of quantitative and qualitative tests that will measure the effectiveness of the serve. The learning engines are the same without distinction of age and training can improve in pass that in both types of service. It would therefore demonstrate the futility of obligatory service underhand and propose makes it possible to high float in both sexes also for the categories under 12 and under 13 and leave the mandatory service underhand only in the super mini volleyball.

\section{CONCLUSIONS}

From the pilot study data will be obtained and interpretations useful for an experimental study large and detailed, or will be obtained with the method further indications of the pilot work. Therefore, the preliminary study may allow to address the issue of compulsory service underhand, as a way to promote continuity in the actions of the game, in both sexes of the two age groups are included. In addition, avoid personal pronouns statistical data will be examined to determine whether it is best mixed activities, where children aged 12 and 13 years of both sexes train together, where are listed specific rules on service. "The results will be useful for identifying the errors and to analyze the causes, to suggest different ways of analysis and self-analysis of technical movements for educational purposes, and also for a hypothetical different way to teach specific technical gestures, using video feedback" (Raiola et al., 2013). 


\section{REFERENCES}

1. Raiola, G. (2012a) Bodily communication in volleyball between human and experimental sciences. Mediterranean Journal of Social Sciences, 3(1), pp.587-597.

2. Raiola, G. (2012b). Didactics of volleyball into the educate program for coaches/trainers/technicians of Italian Federation of Volleyball (FIPAV). Physical Education and Sport, 12(1), pp.25-29.

3. Raiola, G. (2012c). Didactics of volleyball into the educate program for coaches/trainers/technicians of Italian federation of volleyball, Journal of Physical Education And Sport, 12(1) pp. 25-29.

4. Raiola, G., Parisi, F., giugno, Y. \& Di Tore, P.A. (2013). Video analysis applied to volleyball didactics to improve sport skills. J Hum Sport Exerc, 8(2), pp.307-313.

5. Raiola, G. (2011). Theoretical, argumentative and empirical volleyball study on body communication and its relation to anticipation skills: New perspectives of coaching formation. Acta Kinesiologica, 5(2), pp. 22-30. 